\title{
Case Study on Safety Assessment of Rockfall and Splash Stone Protective Structures for Secondary Excavation of Highway Slope
}

\author{
Guan Jiang, ${ }^{1}$ Zhongju Feng $\mathbb{D}^{1},{ }^{1}$ Ruixin Zhao, ${ }^{1}$ Fuchun Wang, ${ }^{1}$ Xiang Yu, ${ }^{1}$ Min Wu, \\ and Zhengxu Zhang ${ }^{2}$ \\ ${ }^{1}$ School of Highway, Chang'an University, Xi'an 710064, China \\ ${ }^{2}$ Qilu Transportation Development Group, Jinan 250014, China \\ Correspondence should be addressed to Zhongju Feng; ysf@gl.chd.edu.cn
}

Received 10 November 2019; Revised 2 November 2020; Accepted 14 December 2020; Published 4 January 2021

Academic Editor: Andreas Lampropoulos

Copyright (C) 2021 Guan Jiang et al. This is an open access article distributed under the Creative Commons Attribution License, which permits unrestricted use, distribution, and reproduction in any medium, provided the original work is properly cited.

Rockfall occurs on the excavation of the slope of highway resulting from excavated rock pieces. In order to solve the problem of rockfall protection during the disturbance of high slope secondary excavation, rockfall analysis program RocFall was used to perform inverse calculation for rockfall path of excavation disturbed rock. Based on a case study of a reconstruction and expansion project, two rockfall movement models were proposed under excavation disturbance. Moreover, the safety of protective structures under five protection schemes and different initial rockfall movement points is evaluated according to the rockfall interceptions rate. The evaluation results were further verified by long-term field observation. The results show that the protective structure at the slope top has a better interception effect to rockfall. It was difficult to intercept the splash stone, which threats to the traffic safety of the existing roads. According to different construction points of mechanical excavation and the interception rate of splash stone by the protective structure, the forbidden region and safety region of mechanical excavation were proposed.

\section{Introduction}

Rockfall refers to one or several movements (falling, collision, rebound, rolling, and sliding), in which the dangerous rock in the upper part of the slope moves away from the rock mass under gravity and external force and moves down the slope $[1,2]$.

Rock collapse, because of its sudden strong, unpredictable, and rapid characteristics, has become a hotspot in the study field of landslide monitor [3]. With the construction of highways in mountains and the excavation of high slopes, the problem of rockfall has become increasingly serious and attracted more attention. In 1980, Bozzolo and Pamini [4] and Gumus et al. [5] proposed the five-point theoretical hypothesis of the rockfall movement, which laid a foundation for the study of rockfall problem. Since then, the study of the rockfall movement has been divided into two types. The first type of study regards the falling rock as a mass point, and motion parameters and slope material have influence on the motion trajectory [6]. The second type considers the shape and volume of the falling rock and analyzes the motion pattern and collision process of the falling rock based on the contact mechanics theory [7]. As for the research methods, some scholars use the probabilistic analysis method to analyze the influence degree of different factors on the movement distance of falling rock and determine the main factors affecting the movement trajectory $[1,8-10]$. Cha et al. [11] and Xiao-hui et al. [12] derived the method of calculating rockfall motion parameters by using the theoretical formulas method. Others scholars [13-15] predicted the movement distance and movement path of falling rock by carrying out model test or numerical simulation.

The above research analyzes the movement process of falling rock under gravity or slight disturbance. However, the movement pattern and trajectory of rockfall caused by the construction disturbance are not analyzed. Along with the economic development in China, the amount of road traffic has increased significantly, and a large number of existing roads have been rebuilt and expanded. Scholars are 
increasingly concerned with the rockfall problem during the second excavation of the slope. Compared with the traditional rockfall, rockfall caused by excavation disturbance is flat or obliquely inclined along the slope. The rockfall has high speed, and the speed loss is small after collision with the slope [16-21]. There are great hidden dangers in construction safety during the process of reconstruction and expansion. To solve the problem, this study used rockfall software to analyze the trajectory of dangerous rock under two construction disturbances. The relationship between the initial position of splash stone and the intercept rate of the protective structure was studied. Based on the engineering case, a safety protection scheme was adopted by the site construction, and corresponding construction suggestions were proposed.

\section{Project Overview}

2.1. Project Background. Beijing-Shanghai highway was built as the first national trunk highway in China. It is of great significance to promote economic development along the route. However, due to the increase in the traffic volume, the existing highway can hardly meet the growing travel demands, and some reconstruction and expansion projects have been launched. According to the plan, the Laiwu-Linyi section of the Beijing-Shanghai Expressway was changed from the original two-way four-lane highway to eight-lane highway. It is necessary to ensure the smooth flow of the highway during the construction process and strictly forbid closing the existing highway lane, falling into the existing road surface or affecting the normal traffic. Moreover, strict requirements have been put forward for the protection of rock falling during the secondary excavation of slopes.

The topography and geomorphology along the reconstructed Laiwu-Linyi section of the Beijing-Shanghai highway include low mountains, hills, terraces, floodplains, and riverbed. The terrain is folded, and the thickness of the quaternary cover along the line is uneven. The underlying rock formations are mainly limestone, marl, shale, mixed granite, etc. The geological conditions are more complicated. A large number of rocky high cutting slopes were secondary excavation on the reconstruction and expansion project of the Laiwu-Linyi section of the Beijing-Shanghai highway. The relationship between slope and geographical position of the highway is shown in Figure 1.

\subsection{Site Construction Overview}

2.2.1. Excavation Process. According to the requirements for secondary excavation, mechanical excavation was used to control the falling rock in the project. Before the excavation, the construction personnel performed measurement at the top of the slope, released the excavation side line, and installed the isolation grid outside the excavation side line to ensure the closed construction. The rockfall protection structure was set on the slope surface, and the rock mass was crushed by a hydraulic breaker. The construction personnel monitored and measured the slope in the entire excavation process. A Korean original DBL1400 hydraulic breaker was used to crush rock mass, with the impact frequency of $350 \sim 500 \mathrm{~Hz}$ and the maximum impact energy of $513 \mathrm{~J}$. Due to the large impact energy, a large amount of debris were splashed during the crushing process. The stone excavation was performed from top to toe in vertical layer excavation and while the sequence was from the inside to the outside in horizontal layer excavation, as shown in Figure 2.

2.2.2. Rockfall Protection. A protective structure composed of a bamboo retaining and a seamless steel pipe was adopted to intercept the falling rock of slope. The protective structure is shown in Figure 3.

Steel pipe: DN70 seamless steel pipes were used. The thickness was $5 \mathrm{~mm}$ and the material type was Q235.

Bamboo retaining: the thickness was $35 \mathrm{~mm}$, width was $300 \mathrm{~mm}$, and the material type was flexible structure.

\section{Model Establishment and Parameter Selection}

3.1. RocFall Calculation Principle. Rockfall trajectory analysis software (RocFall) was selected to analyze the rockfall path. RocFall is a 2D statistical analysis program designed to assist with the assessment of slopes at risk for rockfalls. Lumped mass and rigid body were allowed to analyze rockfall in RocFall. Rockfall mitigation tools can be added, including barriers and earthen berms. Distributions of energy, velocity, and bounce height as well as the location of rock endpoints are calculated along the slope profile. After the dangerous rock mass in the upper part of the slope was disturbed, it moved downward under the action of gravity, and the potential energy was gradually converted into kinetic energy, which was gravity acceleration. When the falling rock collided with the slope and rebounded, the speed of the falling rock was determined by the normal and tangential recovery coefficient of the slope, and the friction coefficient of the slope influenced the speed direction. Because of the collision, the kinetic energy of the falling rock decreased until the kinetic energy decayed to zero. In this case, the falling rock stopped moving, and the entire movement followed the energy conservation and transformation law.

3.2. Slope Geological Model. This study selects the typical $\mathrm{K} 503+585 \sim 504+018$ slope. It shows the steep-to-slow trend from top to toe. It is a six-level uniform slope with $45.7 \mathrm{~m}$ height. The slopes of the first to the third grades are $8 \mathrm{~m}$ height. Additionally, height of the 4 th and 5 th grade slopes is $10 \mathrm{~m}$ and $9 \mathrm{~m}$, respectively. Height of the 6 th grade slopes is $2.7 \mathrm{~m}$. The top surface of the slope is approximately horizontal (see Figure 4), and the full slope surface is the shotcrete.

\subsection{Parameter Selection}

3.3.1. Determination of Slope Material Parameters. Rockfall collision bounce is one of the most complicated and uncertain motions in rockfall movement. Rockfall collision 

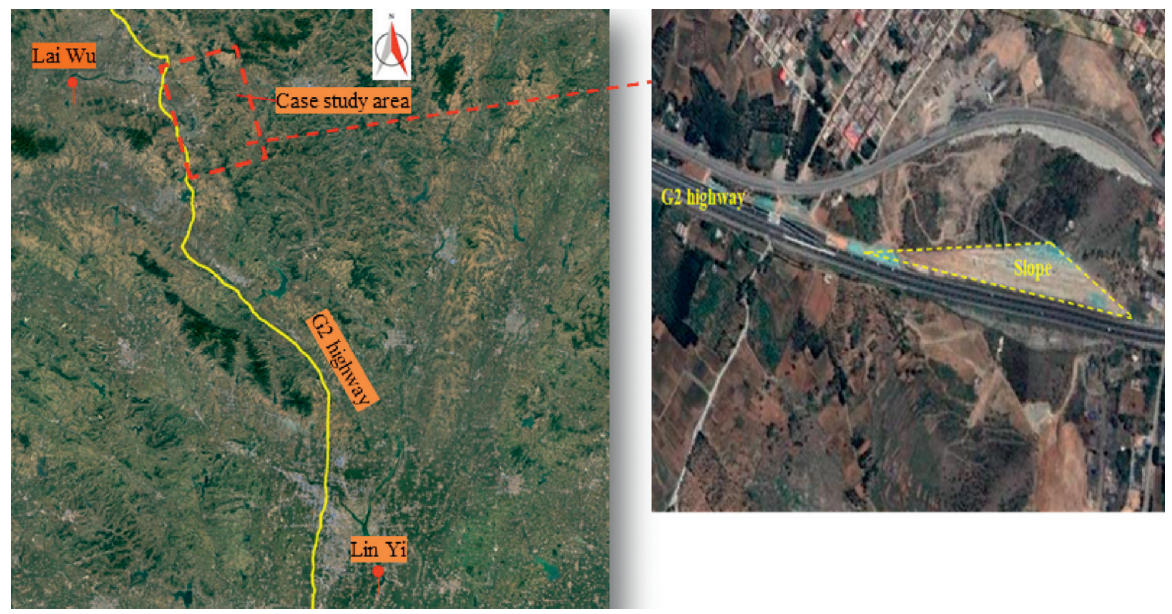

FIgURE 1: The relationship between slope and geographical position of the highway.

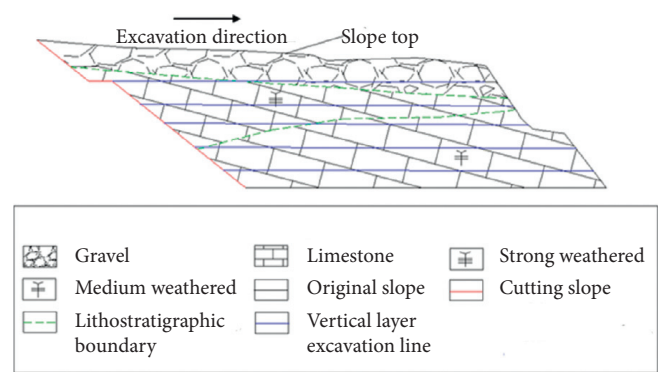

(a)

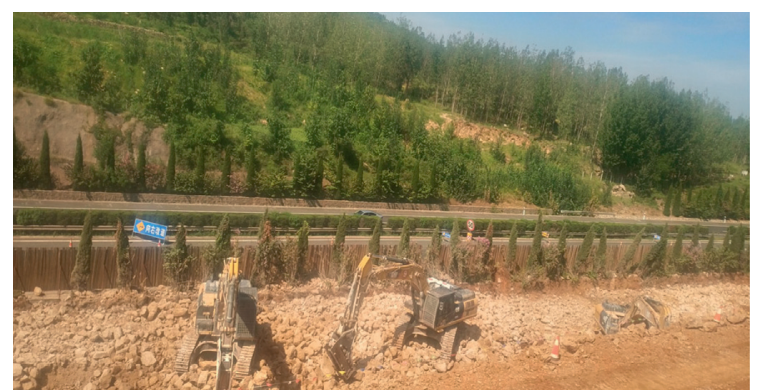

(b)

FIGURE 2: Scheme of mechanical excavation in K503 + 585 504 + 018 slope. (a) Schematic of the road excavation; (b) mechanical excavation on site.

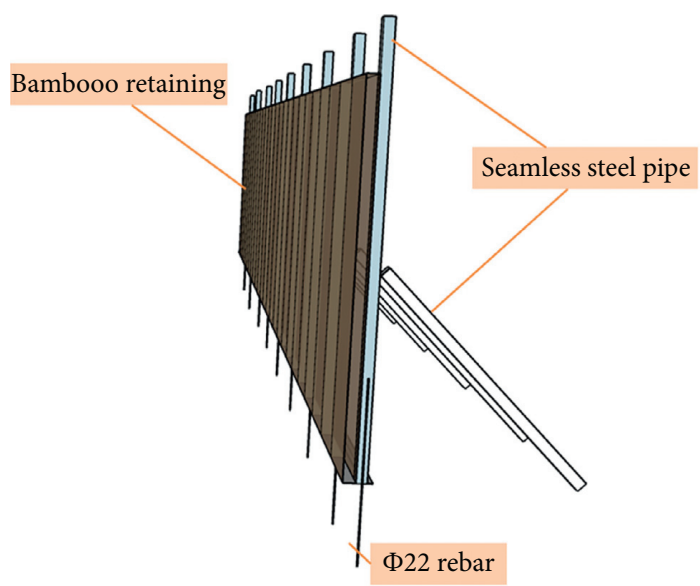

FIGURE 3: Composition of the protective structure in $\mathrm{K} 503+$ $585 \sim 504+018$ slope.

is regarded as a rigid body collision, and the energy loss in the collision is considered by the recovery coefficient. In the process of rockfall collision, nonlinear deformation and friction are more in accord with engineering practice. According to the literatures [22-25], in addition to the physical and mechanical properties of the slope, factors such as rockfall shape, slope morphology, slope degree, drop height, incident velocity, and angle of incidence can also influence the rockfall collision recovery coefficient. The interval value is taken for the collision recovery coefficient of the slope material, so that the normal and tangential collision recovery coefficients fluctuate within a certain interval.

According to the test results of Chau et al. [11] and Giani et al. [26], the mean values of the normal and tangential recovery coefficients of shotcrete are 0.453 and 0.737 , respectively. Considering the difference of concrete as an artificial material, the standard deviation of the normal and tangential recovery coefficients is taken as $s^{*}=0.01$.

In the RocFall software, the input friction angle is the friction coefficient. According to the test results of Chau et al. [11], the static friction coefficient of shotcrete is 0.559 . Considering the difference of concrete with different mix ratios in surface roughness, the friction angle of the slope material takes the interval value, and the mean value of the friction angle is calculated by the inverse trigonometric function. The ratio is $29.2^{\circ}$ and the standard deviation is taken as $s^{*}=0.4^{\circ}$.

\subsubsection{Falling Rock Parameters of Manual Disturbance.} When the construction personnel conduct measurement and stakeout at the top of the slope, they may touch the 


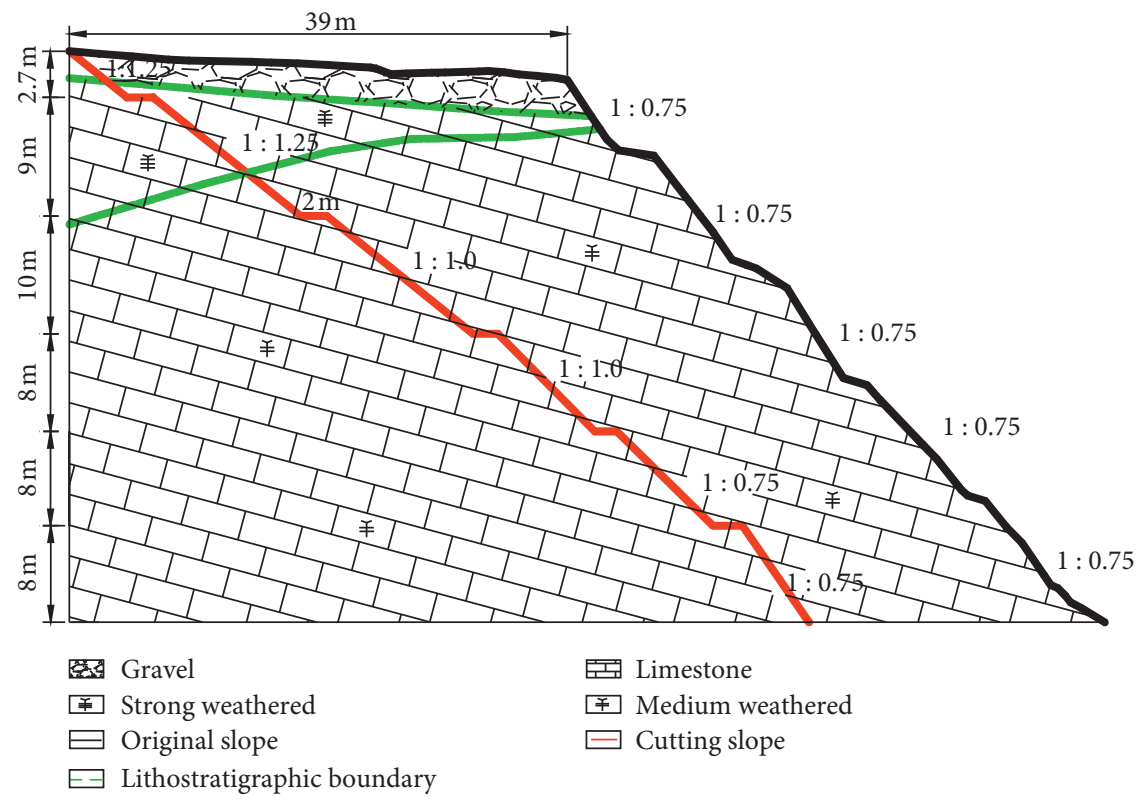

FIGURE 4: Geologic profile in K503 + 585 504+018 slope.

gravel and fall from the top of the slope during the walking process. The crushed rock will produce a horizontal speed after being touched, and the movement mode is to flatten down the top of the slope. To throw the motion, it is only necessary to determine the horizontal velocity $V_{0}$ and the mass $m$ of the gravel at the initial moment to calculate the trajectory of the rockfall.

Assume that the normal walking speed of adult male is $V_{w}$, the step is $S$, and the time required to take one step is $t$. The sole is first accelerated and then decelerated in the process of taking one step, and the whole step is in progress. The velocity-time function obeys the sine function, and the expression is (1) (2). $A$ is the instantaneous maximum velocity of the soles in the process of taking a step.

$$
\begin{aligned}
& t=\frac{S}{V_{w}}, \\
& y=\left|A \sin \frac{S}{V_{w}} x\right| .
\end{aligned}
$$

Since the distance of a step is equal to that calculated using the average walking speed in time $t$, there are

$$
\int_{0}^{t}\left|A \sin \frac{\pi v_{w}}{S} x\right| \mathrm{d} x=\int_{0}^{t} v_{w} \mathrm{~d} x
$$

where $t$ is the time taken for a normal adult male to walk one step (s); $V_{w}$ is the walking speed of a normal adult male $(\mathrm{m} / \mathrm{s})$; $A$ is the maximum walking speed of a normal adult male $(\mathrm{m} / \mathrm{s})$; $S$ is the walking step distance of a normal adult male $(\mathrm{m})$.

The walking speed of a normal adult is about $1.4 \mathrm{~m} / \mathrm{s}$, the step distance is $0.60 \mathrm{~m}-0.75 \mathrm{~m}$, and the instantaneous maximum speed $A$ of the feet is $2.2 \mathrm{~m} / \mathrm{s}$ in a step. Assume that the sole touches the gravel at maximum speed. The feet are considered to transmit the full speed to the gravel without considering the speed loss.
The size of multiple groups of gravel was measured at the top of the slope, and the average diameter of the crushed rock is $4 \mathrm{~cm}$, as shown in Figure 5. It is calculated according to the volume formula of the sphere. The limestone density is $2.7 \mathrm{~g} / \mathrm{cm}^{3}$, and the mass of the crushed rock is $0.26 \mathrm{~kg}$.

3.3.3. Splash Stone Parameters of Mechanical Excavation. Mechanical excavation of broken rock mass will splash debris. In this study, the rockfall caused by mechanical excavation is defined as splash rock. During the process of rock splashing, the breaker impacts the rock mass. The deformation of the rock body extruded the debris to generate horizontal velocity $\left(V_{0}\right)$ and vertical velocity $\left(V_{1}\right)$. Oblique dancing is performed along the original ground. Since the velocity of debris splashing during the rock mass crushing process cannot be directly calculated, the debris movement track at the horizontal distance of $5 \mathrm{~m}$ from the breaker is manually observed at the construction site. When the observed debris passed over the shoulder of the observer, its trajectory is approximately horizontal, and the observer's shoulder was $1.5 \mathrm{~m}$ away from the ground. Considering the different strokes of breakers and the approximation of the estimation, the interval value of the movement speed of the rock is taken. Through the back calculation of the motion trajectory, the average horizontal velocity $V_{0}=9.13 \mathrm{~m} / \mathrm{s}$ and the average vertical velocity $V_{1}=5.48 \mathrm{~m} / \mathrm{s}$ were obtained, and the standard deviation $s^{*}=0.4 \mathrm{~m} / \mathrm{s}$ was given to both the horizontal velocity and the vertical velocity.

The particle size of the slabs of debris was measured at the site as shown in Figure 6. The average diameter of the debris was $1 \mathrm{~cm}$, and the density of the limestone was calculated. The mass of the spheroid was $0.01 \mathrm{~kg}$.

Construction of hydraulic breakers in the secondary excavation was along the longitudinal direction of the slope. Since the debris was splashed during the crushing process, 


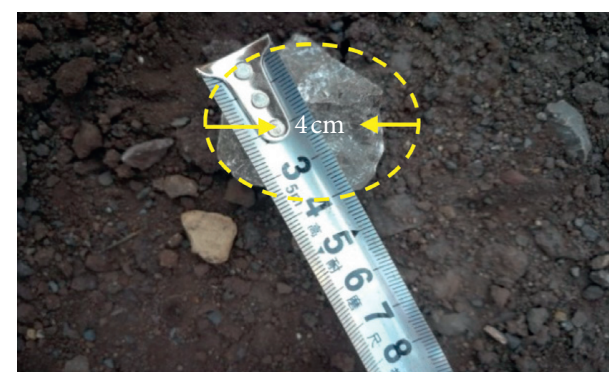

Figure 5: The size of rockfall in K503+585 504+018 slope.

the initial movement point of the splash stone changed with the crushing point of the hydraulic breaker. The distance between the secondary excavation line and the original slope is $39 \mathrm{~m}$. Considering the debris during the crushing process, the oblique throwing motion was performed. The plan adopted bamboo protection with the height of $2 \mathrm{~m}$ and $1.5 \mathrm{~m}$ at the toe of the slope and the top of the slope, respectively. The initial movement point of the sloping rock in the longitudinal excavation length of the slope was simulated to influence the rock blocking rate of the protective structure, and the safety was evaluated. The initial point placement scheme selects the point $0.5 \mathrm{~m}$ away from the slope protection structure as the starting point and sets a point every $0.5 \mathrm{~m}$ from the outside to the inside along the longitudinal excavation length of the slope. The distance from the last point to the slope protection structure is $11.0 \mathrm{~m}$.

\section{Safety Evaluation of Rockfall and Splash Stone}

4.1. Safety Evaluation of Rockfall for Manual Disturbance. According to the design scheme of the falling rock protection, several sets of protective structures were set to change the working condition of the position, and the starting point of the falling rock movement was selected at the shoulder of the slope. The layout scheme of the falling rock protection is shown in Table 1 .

According to the simulation scheme, the parameters are substituted into the RocFall software. The histogram of the rock blocking rate in different protection schemes is obtained, and several typical rockfall motion trajectories are selected from the results, as shown in Figures 7 and 8 .

It can be seen from Figures 7 and 8 that as the protective structure moves along the slope surface in different schemes, the interception rate of the falling safe structure increases. According to the theory proposed by Azzoni [22], the movement pattern of rockfall on the slope only depends on its $V_{y}$ at this point. Therefore, there is a critical velocity $V<V_{e}$. When, the falling rockrolled down the slope. When $V>V_{e}$, the falling rock will fall freely along the slope, and its trajectory can be approximated as a flat throwing motion. The falling rock will rebound after colliding with the slope at the velocity, instead of continuing scrolling down the slope. Combined with the above theory, the trajectories in different protection schemes and the interception rate of rockfall were analyzed. When the falling rock falls from the top of the slope, the critical speed has not yet been reached because of

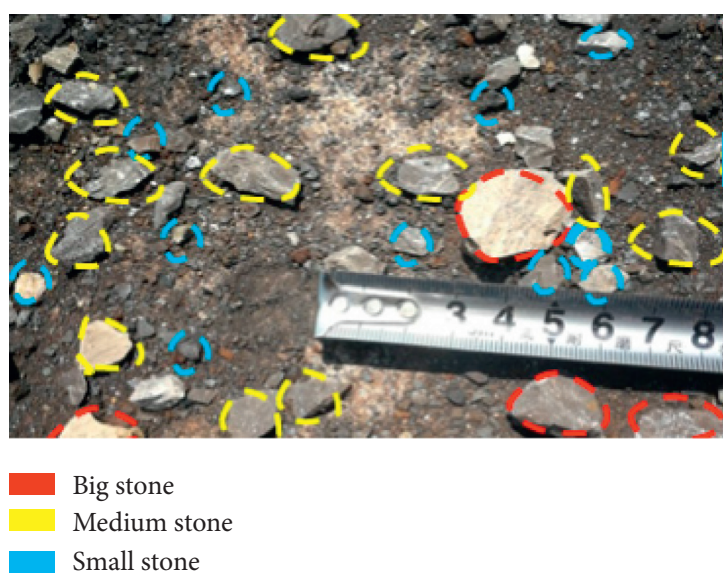

Figure 6: Particle size of splash stone at the site.

the low vertical velocity, and the movement track of the falling rock is close to the slope. If the protective structure was set on the movement trajectory to effectively block the falling rock, schemes 4 and 5 which select the protective structure at the top of the slope and the third-stage platform are better, and the interception rate of the falling rock is $100 \%$. As the potential energy gradually converted into kinetic energy during the rock falling, the vertical velocity of the falling rock increases continuously. When the critical speed $V_{y}$ is reached, the falling rock leaves the slope to make a flat throwing motion.

The horizontal moving distance of the falling rock increases, and some falling rock falls over the protective structure to the highway. The protective structure has a poor rock blocking effect. Based on the comprehensive analysis, it is concluded that schemes 4 and 5 have better rock barrier effects and higher safety than other schemes. In the meanwhile, splash stone was greatly intercepted rate by protective structure at slope top, and scheme 5 has better rockfall and splash stone barrier effect. $1.6 \mathrm{~m}, 1.8 \mathrm{~m}, 2.0 \mathrm{~m}$, and $2.2 \mathrm{~m}$ height protections were selected, respectively, which was set at the slope toe. The effects of different height protective structures on the interception rate of rockfall were studied, and four different height protective structure interpretation results were obtained, as shown in Figure 9.

It can be seen from Figure 9 that $2.2 \mathrm{~m}$ height protective structure at slope toe was better interpretation rate. The height of the protective structure is increased from $1.6 \mathrm{~m}$ to $2.0 \mathrm{~m}$, and the interception effect is significantly enhanced. Considering the stability of the protection structure, $2.0 \mathrm{~m}$ height of protection structure was selected.

\subsection{Safety Evaluation of Splash Rock for Mechanical} Excavation. Hydraulic breakers in the secondary excavation were along the longitudinal direction of the slope. Since the debris was splashed during the crushing process, the initial movement point of the splash rock changed with the crushing point of the hydraulic breaker. The distance between the secondary excavation line and the original slope is $39 \mathrm{~m}$. Considering the debris during the crushing process, the oblique throwing motion was performed. The plan 
TABLE 1: Rockfall protection scheme.

\begin{tabular}{lc}
\hline Scheme & Arrangement \\
\hline 1 & $2 \mathrm{~m}$ height protective structure at slope toe $+1.5 \mathrm{~m}$ bamboo retaining at first platform \\
2 & $2 \mathrm{~m}$ height bamboo retaining at slope toe $+1.5 \mathrm{~m}$ bamboo retaining at second platform \\
3 & $2 \mathrm{~m}$ bamboo retaining at slope toe $+1.5 \mathrm{~m}$ bamboo retaining at third platform \\
4 & $2 \mathrm{~m}$ bamboo retaining at slope toe $+1.5 \mathrm{~m}$ bamboo retaining at slope top \\
\hline
\end{tabular}

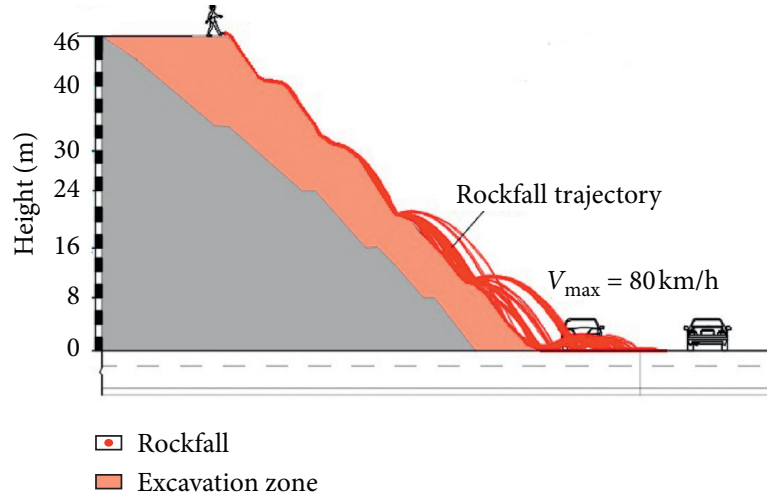

(a)

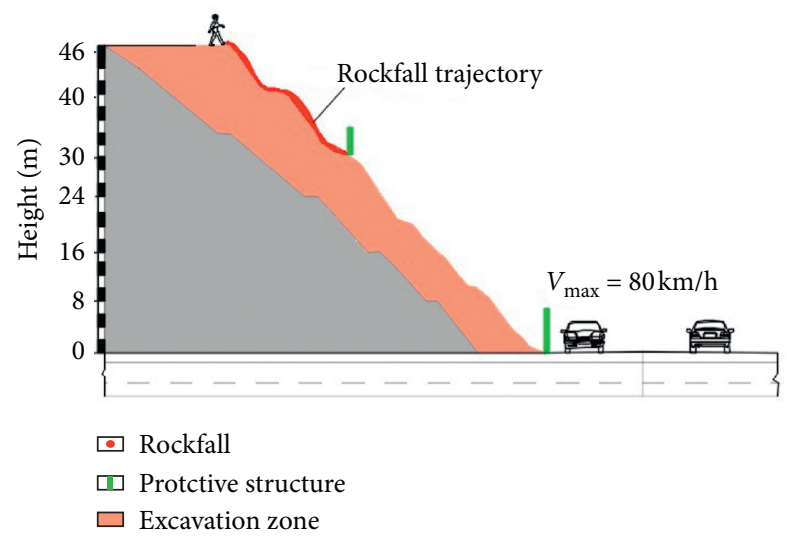

(b)

FIGURE 7: Trajectories of fall rock in different protection schemes (a) no protection structure (b) protection structure at three grade slope platform.

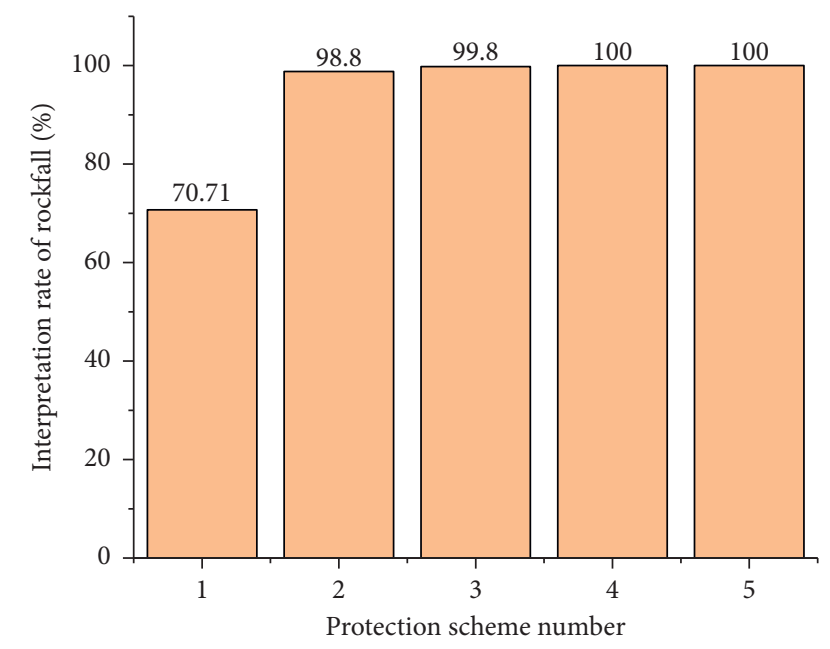

FIGURE 8: Five protection schemes for the rockfall interception rate.

adopted bamboo retaining protection with the height of $2.0 \mathrm{~m}$ and $1.5 \mathrm{~m}$ at the foot of the slope and the top of the slope, respectively. The initial movement point of the sloping rock in the longitudinal excavation length of the slope was simulated to influence the rock blocking rate of the protective structure, and the safety was evaluated. The initial point placement scheme selects the point $0.5 \mathrm{~m}$ away from the slope protection structure as the starting point, and a point every $0.5 \mathrm{~m}$ from the outside to the inside along the longitudinal excavation length of the slope was set. The

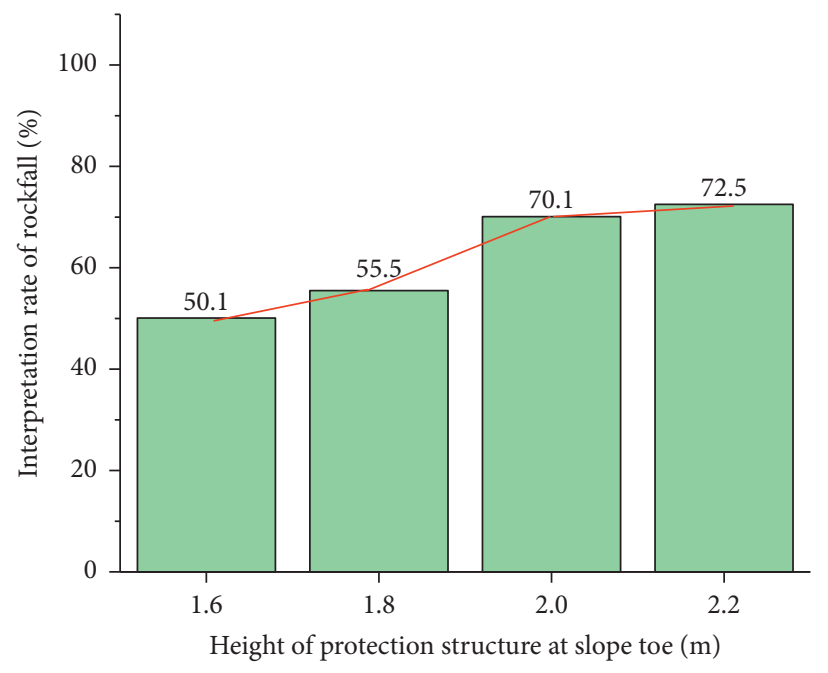

FIGURE 9: Rockfall interception rate under different heights protection structure at slope toe.

distance from the last point to the slope protection structure is $11.0 \mathrm{~m}$.

Several initial positions of the splashing stone were taken along a certain distance in the longitudinal excavation length of the slope. The interception rate and the motion trajectory map of each initial point were obtained. Several sets of typical trajectories were selected, and the data of different initial point trajectory interception rates were plotted as a line chart. The final results are shown in Figures 10 and 11. 


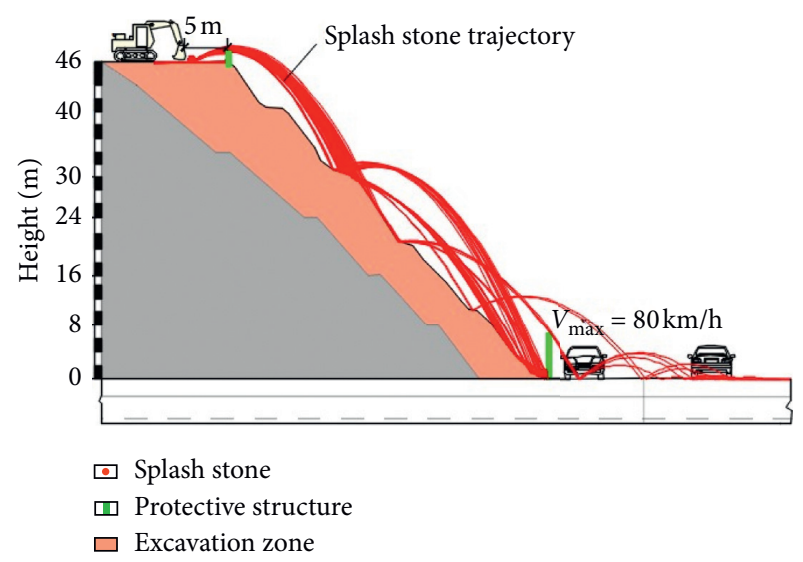

(a)

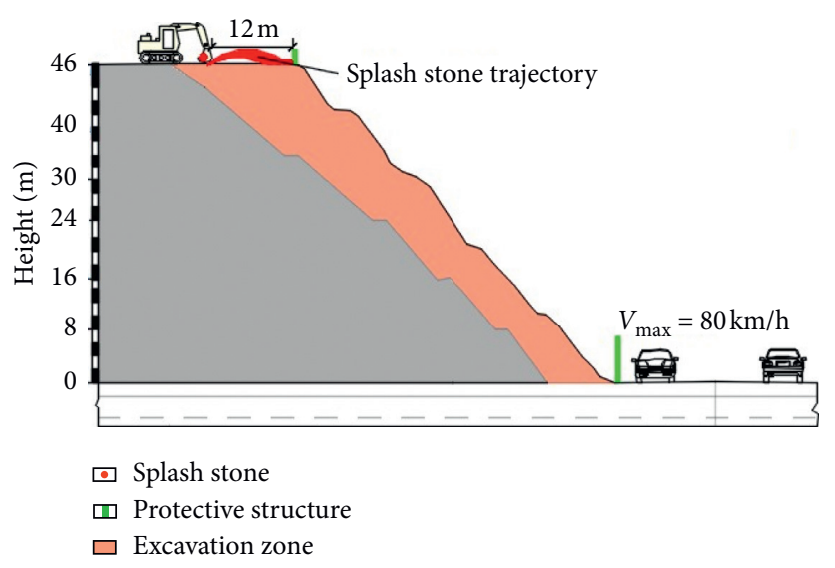

(b)

Figure 10: Splash stone trajectory of different distance (a) $5 \mathrm{~m}$ from the protective structure (b) $12 \mathrm{~m}$ from the protective structure.

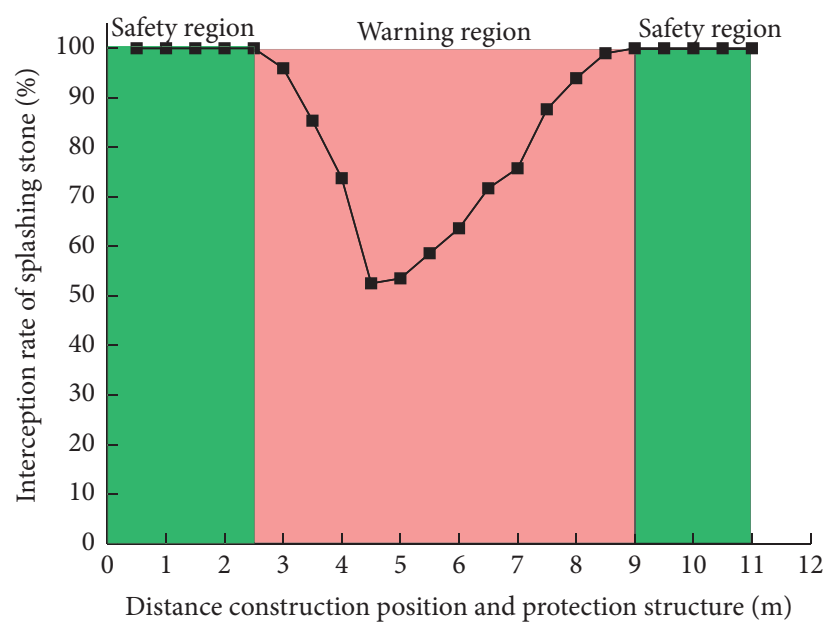

FIGURE 11: Relationship between initial movement point of splash stone and interception rate of protective structure.

Figure 10 shows the motion trajectory diagrams of the initial movement point of the splashed stone from the top of the slope at $5 \mathrm{~m}$ and $12 \mathrm{~m}$, respectively. It can be seen that the splashing stone crossed the protective structure and then made a flat throwing motion. After the splashing rock collided with the slope surface, the trajectory was gradually away from the slope surface. Finally, most of the rockfall is blocked by the bamboo retaining set by the slope foot, and a small part falls to the highway. The initial point height of the flat throwing motion is higher than the splashing rock of the bamboo retaining. Considering the approximation of the initial velocity estimation of the splash rock, the motion trajectory and the final falling point are uncertain. Therefore, this study analyzes the relationship between the interception rate of the slope protection structure and the initial movement point of different splashes, without considering the protective structure of the rock at the toe of the slope.

As can be seen from Figure 11, due to the inclined movement of the splashed stone in the hydraulic breaker, the initial horizontal velocity $V_{0}$ is greater than the vertical velocity $V_{1}$. When the starting point of the splash stone was closer to the protection, the vertical movement of the falling rock did not reach the height of the bamboo retaining, and the splash stone was blocked by the bamboo retaining in the horizontal moving direction. The point was determined by its horizontal motion. The rock cannot cross the baffle, and the intercept rate was $100 \%$. As the distance between the starting point of the splash and the baffle increased, the horizontal movement time of the incline throwing motion was extended. The vertical movement of the splash stone had enough time to reach or exceed the height of the bamboo retaining, and the splash stone crossed the bamboo retaining. When rock fell to the slope, the interception rate decreased continuously with the increase of the horizontal spacing. At the spacing of $3 \mathrm{~m}$, the interception rate decreased from $100 \%$ to $95.96 \%$ and reached the lowest of $52.53 \%$ at the interval of $4.5 \mathrm{~m}$. When this distance was exceeded, the horizontal movement of the splash stone was large. After the vertical movement reached the highest point, the splash stone did not move to the position of the bamboo retaining in the horizontal direction. After the throwing movement, the height was gradually reduced, and the rock 


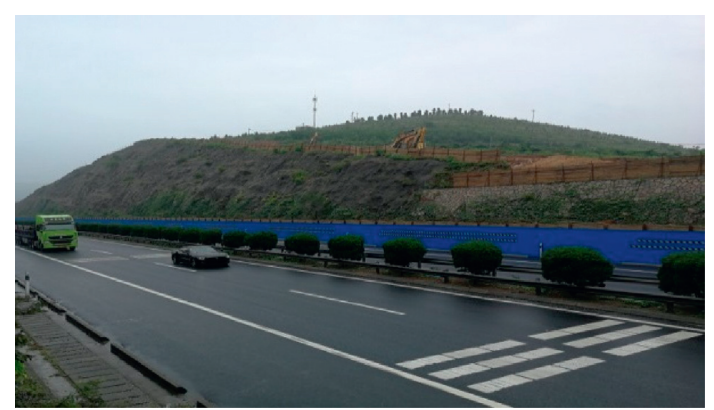

(a)

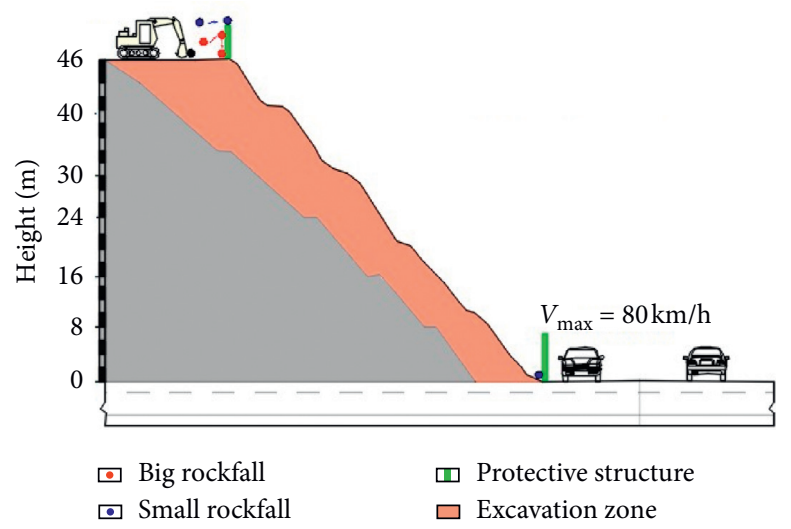

(b)

FIGURE 12: Highway road on the site during the construction: (a) observation highway road on the site and (b) schematic diagram of construction site.

was finally blocked by the bamboo retaining or the ground. The interception rate increased with the increase of the spacing. When the distance between the starting point and the baffle plate was $9.5 \mathrm{~m}$, the rock was completely blocked by the bamboo retaining and the ground, and the interception rate was restored to $100 \%$.

According to the above analysis, combined with the requirements of the falling rock control at the construction site, the mechanical excavation area within the range of $3 \sim 9.5 \mathrm{~m}$ from the horizontal protection structure of the slope top is prohibited. It is not recommended to use the broken hammer for crushing construction in this range. The ranges of $2 \sim 3 \mathrm{~m}$ and $9.5 \sim 11.0 \mathrm{~m}$ are the warning zone. In this range, the mechanical crushing and excavation method should be used cautiously. Other ranges $(9.5 \mathrm{~m} \sim 39 \mathrm{~m}$ and $0 \sim 2 \mathrm{~m})$ are used for safe areas. Therefore, hydraulic breakers are recommended for construction.

4.3. Field Verification and Evaluation. In the final support plan, the bamboo retaining protection was set at the height of $1.5 \mathrm{~m}$ at the top of the slope and $2 \mathrm{~m}$ at the foot of the slope, as shown in Figure 12. After a year of construction, the on-site construction personnel observed that there was no rock falling on the road surface, and the roads were safe.

4.4. Research Prospect. Under the disturbance of the secondary excavation of the reconstructed rock slope, the rockfall affects the operation of the highway. To ensure the safety of passengers and drivers during the rock slope excavation, the trajectory of rockfall and splash stone was analyzed during the secondary excavation. According to the interception rate index of falling rock, the characteristics of the warning zone and the rockfall movement in different support schemes during the construction process were proposed. This study did not consider the warning area of rock splashing supporting scheme in the slope blasting construction. The next step is to study warning areas under various blasting processes and different supporting schemes. Considering the construction cost, the optimum baffle support height is obtained. To meet the practical needs of engineering, the calculation and analysis of rockfall are simplified appropriately, and the rockfall is idealized as a sphere. In fact, the trajectory of the rockfall can be influenced by various factors. Scholars all over the world have carried out relevant studies in multiple directions. Future production and research work should explore the influence of the mass and shape of falling rock, as well as the collision of large falling rock on the trajectory, and establish a complete rockfall evaluation system.

\section{Conclusions and Construction Suggestion}

The trajectories of rockfall and splash stone were analyzed in two construction disturbance models, and the effects of rock interception under different protection schemes were compared combined with the relationship between the initial point of splashing stone and the interception rate of protective structure. The following conclusions and suggestions are obtained:

(1) Rockfall caused by artificial disturbance during construction should be set as close as possible to the top of the slope, and bamboo retaining as rockfall and splash stone protective structure was applied to secondary excavation of highway slope.

(2) According to the prohibited mechanical excavation area $(3 \sim 9.5 \mathrm{~m})$ and the warning area $(2 \sim 3 \mathrm{~m}$ and 9.5 11 m) for the rock movement, appropriate excavation method, artificial crushing, and excavation should be adopted in the area where mechanical excavation is prohibited. The small-stroke breaker can be used in the warning area and the power can be reduced. The artificial excavation should be appropriately assisted.

(3) Protective structure was set on both slope top and toe can effective interception rockfall and splash tone; both $1.5 \mathrm{~m}$ height at the slope top and $2.0 \mathrm{~m}$ height at the slope toe suggest were selected.

(4) Attention should be paid to the effect of the slope top protection structure on the splash rock, and the 
splashing stone should be prevented from being blocked by the slope top. When the protective structure cannot effectively block the splash stone, the height of the protective structure can be appropriately increased.

\section{Data Availability}

The data used to support the findings of this study are available from the corresponding author upon request.

\section{Conflicts of Interest}

The authors declare no conflicts of interest.

\section{Acknowledgments}

The authors are very grateful for the Fundamental Research Funds for the Central University with Grant no. 300102218115.

\section{References}

[1] F. Guzzetti, G. Crosta, R. Detti, and F. Agliardi, "Stone: a computer program for the three-dimensional simulation of rock-falls," Computers \& Geosciences, vol. 28, no. 9, pp. 1079-1093, 2002.

[2] D. J. Varnes, "Slope movement types and processes," in Landslides: Analysis \& Control, R. L. Schuster and R. J. Krizek, Eds., National Academy of Sciences, Washington, DC, USA, 1978.

[3] X. Wang, Y. Xia, and T. Zhou, "Theoretical analysis of rockfall impacts on the soil cushion layer of protective structures," Advances in Civil Engineering, vol. 2018, Article ID 9324956, 18 pages, 2018.

[4] D. Bozzolo and R. Pamini, Modello Matematico per lo Studio della Caduta dei Massi, Laboratorio di Fisica Terrestre-ICTS, Lugano, Switzerland, 1982.

[5] S. Gumus, B. Aricak, K. Enez et al., "Analysis of tree damage caused by rockfall at forest road construction works," Croatian Journal of Forest Engineering, vol. 30, no. 2, pp. 151-158, 2009.

[6] D. Bertrand, A. Trad, A. Limam et al., "Full-scale dynamic analysis of an innovative rockfall fence under impact using the discrete element method: from the local scale to the structure scale," Rock Mechanics and Rock Engineering, vol. 45, no. 5, pp. 885-900, 2012.

[7] R. I. Leine, A. Schweizer, M. Christen, J. Glover, P. Bartelt, and W. Gerber, "Simulation of rockfall trajectories with consideration of rock shape," Multibody System Dynamics, vol. 32, no. 2, pp. 241-271, 2013.

[8] J.-P. Plassiard and F.-V. Donzé, "Rockfall impact parameters on embankments: a discrete element method analysis," Structural Engineering International, vol. 19, no. 3, pp. 333341, 2009.

[9] S. Lambert and F. Bourrier, "Design of rockfall protection embankments: a review," Engineering Geology, vol. 154, pp. 77-88, 2013.

[10] A. M. Fanos and B. Pradhan, "Multi-scenario rockfall hazard assessment using LiDAR data and GIS," Geotechnical and Geological Engineering, vol. 34, no. 5, pp. 1375-1393, 2016.

[11] K. T. Chau, R. H. C. Wong, and C. F. Lee, "Rockfall problems in Hong Kong and some new experimental results for coefficients of restitution," International Journal of Rock Mechanics and Mining Sciences, vol. 35, no. 4-5, pp. 662-663, 1998.

[12] S. Xiao-hui, W. Yun-jie, and L.-J. Tao, "Mathematical models and application of unstable rock masses collapsing movement along slopes," Journal of Belting University of Technology, vol. 38, no. 4, pp. 540-543, 2012.

[13] Bo Song, H. Xiao-min, and S. Huang, "Experimental study on the distance of rock falls under different influencing factors," Journal of Sichuan University (Engineering Science Edition), vol. 48 , no. 6 , pp. 1-7, 2016.

[14] L. K. A. Dorren, B. Maier, U. S. Putters et al., "Combining field and modelling techniques to assess rockfall dynamics on a protection forest hillslope in the European Alps," Geomorphology, vol. 57, no. 3-4, pp. 151-167, 2004.

[15] Q.-Y. Zhang, S.-M. Tang, and J.-H. Shen, "Analysis of movement characteristics of collapse rockfall in Maliugou earthquake," Yangtze River, vol. 46, no. 13, pp. 39-41, 2015.

[16] S.-Q Ye, H.-K. Chen, and J. Xu, "Rockfalls movement mode and movement features by field tests," Journal of Civil Architectural \& Environmental Engineering, vol. 33, no. 2, pp. 18-23, 2011.

[17] K. Maegawa, "Experiments on rockfall protection embankments with geogrids and cushions," International Journal of Geomate, vol. 1, 2011.

[18] Ye Si-qiao, G. Shang-qing, and L.-F. Wang, "Research on value of tangential restitution coefficient for rockfall collision," China Railway Science, vol. 39, no. 1, pp. 8-15, 2018.

[19] D. Liu, Y. Si-qiao, and W. Yang, "Model test study of influence factors of horizontal movement of rockfalls," Hydrogeological \& engineering Geology, vol. 40, no. 6, pp. 112-116, 2013.

[20] Y. Zhong-yuan, "Research on perilous rockfall motion trace of road slope," Journal of Highway and Transportation Research and Development, vol. 27, no. 1, pp. 34-38, 2010.

[21] Y.-P. Liu, N. Lei, and G.-J. Li, "Falling rock movement characteristic and reinforcement measures of a high steep slope," Hydrogeology \& Engineering Geology, vol. 1, pp. 30-33, 2005.

[22] A. Azzoni, G. La Barbera, and A. Zaninetti, "Analysis and prediction of rockfalls using a mathematical model," International Journal of Rock Mechanics and Mining Sciences \& Geomechanics Abstracts, vol. 32, no. 7, pp. 709-724, 1995.

[23] M. H. Taherynia, M. Mohammadi, and R. Ajalloeian, "Assessment of slope instability and risk analysis of road cut slopes in Lashotor Pass, Iran," Advances in Civil Engineering, vol. 2014, Article ID 763598, 12 pages, 2014.

[24] F. Bourrier, J. Baroth, and S. Lambert, "Accounting for the variability of rock detachment conditions in designing rockfall protection structures," Natural Hazards, vol. 81, no. 1, pp. $365-385,2016$.

[25] F. Bourrier, L. Dorren, F. Nicot et al., "Toward objective rockfall trajectory simulation using a stochastic impact model," Geomorphology, vol. 110, no. 3-4, pp. 1-79, 2009.

[26] G. P. Giani, A. Giacomini, M. Migliazza, and A. Segalini, "Experimental and theoretical studies to improve rock fall analysis and protection work design," Rock Mechanics and Rock Engineering, vol. 37, no. 5, pp. 369-389, 2004. 